\title{
Efficient delivery of recombinant human bone morphogenetic protein (rhBMP-2) with dextran sulfate-chitosan microspheres
}

\author{
YUAN-JUN XIA ${ }^{1}$, HONG XIA ${ }^{1}$, LING CHEN ${ }^{2}$, QING-SHUI YING ${ }^{1}$, XIANG YU ${ }^{1}$, \\ LI-HUA LI ${ }^{1}$, JIAN-HUA WANG ${ }^{1}$ and YING ZHANG ${ }^{1}$
}

\author{
${ }^{1}$ Department of Trauma Orthopedics, Hospital of Orthopaedics, Guangzhou General Hospital of \\ Guangzhou Military Command, Guangzhou, Guangdong 510010; ${ }^{2}$ Department of Traditional Chinese \\ Medicine, Southern Medical University, Guangzhou, Guangdong 510515, P.R. China
}

Received October 14, 2017; Accepted January 22, 2018

DOI: $10.3892 / \mathrm{etm} .2018 .5849$

\begin{abstract}
Bone morphogenetic protein-2 (BMP-2) serves an important role in the development of bone and cartilage. However, administration of BMP-2 protein alone by intravenous delivery is not very effective. Sustained delivery of stabilized BMP-2 by carriers has been proven necessary to improve the osteogenesis effect of BMP-2. The present study constructed a novel drug delivery system using dextran sulfate (DS)-chitosan (CS) microspheres and investigated the efficiency of the delivery system on recombinant human bone morphogenetic protein (rhBMP-2). The microsphere morphology, optimal ratio of DS/CS/rhBMP-2, and drug loading rate and entrapment efficiency of rhBMP-2 CS nanoparticles were determined. L929 cells were used to evaluate the cytotoxicity and effect of DS/CS/rhBMP-2 microspheres on cell proliferation. Differentiation study was conducted using bone marrow mesenchymal stem cells (BMSCs-C57) cells treated with DS/CS/rhBMP-2 microspheres or the control microspheres. The DS/CS/rhBMP-2 microspheres delivery system was successfully established. Subsequent complexation of rhBMP-2-bound DS with polycations afforded well defined microspheres with a diameter of $\sim 250 \mathrm{~nm}$. High protein entrapment efficiency (85.6\%) and loading ratio (47.245) $\mu \mathrm{g} / \mathrm{mg}$ were achieved. Release of rhBMP-2 from resultant microspheres persisted for over 20 days as determined by ELISA assay. The bioactivity of rhBMP-2 encapsulated in the CS/DS microsphere was observed to be well preserved as evidenced by the alkaline phosphatase activity assay and calcium nodule formation of BMSCs-C57 incubated with rhBMP-2-loaded
\end{abstract}

Correspondence to: Professor Ying Zhang, Department of Trauma Orthopedics, Hospital of Orthopaedics, Guangzhou General Hospital of Guangzhou Military Command, 111 Liuhua Road, Guangzhou, Guangdong 510010, P.R. China

E-mail: ying_zhang121@163.com

Key words: recombinant human bone morphogenetic protein-2, chitosan, dextran sulfate, nanometer microsphere, preparation, in vitro release, bone induction microspheres. The results demonstrated that microspheres based on CS-DS polyion complexes were a highly efficient vehicle for delivery of rhBMP-2 protein. The present study may provide novel orientation for bone tissue engineering for repairing and regenerating bone defects.

\section{Introduction}

Bone tissue engineering has been widely applied for repairing and regeneration of bone defects caused by traumatic injury, congenital malformation or surgery for bone cancer (1-3). Existing treatment methods include autogenous, allogenic and synthetic bone grafts (4-6). Among them, autograft is a generally preferred choice of bone grafting material $(7,8)$. However, the application of autograft is limited by the inadequate supply for autograft tissues. Though some reports demonstrated that allografts were effective in vertical ridge augmentation of the atrophic posterior mandible Laino (9), problems like disease transfer and histo-incompatibilities which are very likely to occur in the case of allografts $(10,11)$. Due to the aforementioned limitations, engineered biomaterials combined with growth factors have emerged as an alternative choice in bone repair and regeneration (12). A number of different growth factors, including bone morphogenetic proteins (BMPs), transforming growth factor- $\beta$ (TGF- $\beta$ ), vascular endothelial growth factor (VEGF), fibroblast growth factor (FGF) and insulin growth factor (IGF) have been shown to stimulate bone growth, collagen synthesis and fracture repair both in vitro and in vivo (13-16).

In particular, BMPs are osteoinductive proteins originally identified in demineralized bone and are known to facilitate bone healing without bone tissue transferring (17). Among this group of proteins, it is well known that BMP-2 can promote the healing process of segmental bone defects and the osteogenesis ability of bone marrow stromal cells (BMSCs) $(18,19)$. However, the circulation half-life of BMP-2 is rather short. BMP-2 is easily to be inactivated due to dilution or interaction with enzymes in blood if applied alone by intravenous injection $(20,21)$. Another drawback is that the intravenous injection of BMP-2 alone may produce burst effect, which may lead to soft tissue hematoma and bone absorption phenomenon (22). Therefore, it is necessary to develop appropriate delivery systems for BMP-2 to extend its blood circulation time, achieve 
sustained local lease, and at the same time to avoid the adverse effects such as the burst release (23).

In searching for such delivery system, it is noticed that chitosan (CS), a cationic polysaccharide, has been widely used as a drug carrier due to its good biocompatibility and biodegradability and CS-based microsphere have shown some distinct advantages in delivery of various bio-active species (24). It has been demonstrated that CS-based microspheres as a drug delivery system (DDS) is able to reduce side effects, improve drug stability and enhance therapeutic efficacy of drugs and proteins $(25,26)$.

In our previous study, we successfully prepared rhBMP-2 loaded CS microsphere. However, the entrapment efficiency and drug loading ratio (mass ratio of protein to carrier of the microsphere) were quite low, presumably because of the low binding affinity of CS towards BMP-2. On the other hand, it was reported that dextran sulfate (DS) sodium, a sulfated anionic polysaccharide, showed fairly strong affinity towards proteins, which have heparin or heparan sulfate glycosaminoglycans, such as rhBMP-2 $(27,28)$. Furthermore, it was reported that CS and DS could form stable polyelectrolyte complexes (PECs) which could efficiently encapsulate and stabilize therapeutic proteins $(29,30)$. It has also been demonstrated that heparin sulfate glucose amino glucan could be utilized to adjust the biological activity of exogenous growth factors (31). According to the above, we hypothesized that, by introducing DS as the BMP-2 binding component in to our CS-microsphere delivery vehicles, the encapsulation efficiency would be greatly enhanced. And more importantly, the polyelectrolyte complexes formed by CS and DS might significantly increase the stability of the resulting protein-loaded delivery assembly.

Herein, we reported the preparation of CS/DS based microspheres as an efficient delivery vehicle for recombinant human bone morphogenetic protein-2 (rhBMP-2). Our preliminary study revealed that our CS/DS based microsphere has high entrapment efficiency $(85.6 \pm 3 \%)$ and high drug loading ratio $(47.245 \pm 3.321 \mu \mathrm{g} / \mathrm{mg})$ for rhBMP-2, as well as sustained release kinetics and good osteogenic activity. This study may provide new orientation for bone tissue engineering for repairing and regeneration of bone defects in clinic.

\section{Materials and methods}

Preparation of DS/CS blank microsphere. A certain amount of CS, molecular weight ranging from 50,000-190,000, off $85 \%$ of the acetic acid, Shanghai Aladdin Bio-Chem Technology Co., Ltd., (Shanghai, China) was dissolved in $0.175 \%$ (V/V) acetic acid to prepare $1 \mathrm{mg} / \mathrm{mlCS}$ solution which was then filtered successively through $0.45 \mu \mathrm{m}$-diameter membrane and $0.22 \mu \mathrm{m}$-diameter membrane. DS soluble to double-distilled water was weighed and prepared into $1 \mathrm{mg} / \mathrm{ml} \mathrm{DS}$ solution which was then filtered successively through $0.45 \mu \mathrm{m}$-diameter membrane and $0.22 \mu \mathrm{m}$-diameter membranes. 0.2 ml DS (molecular weight 500,000, Shanghai Aladdin Bio-Chem Technology Co., Ltd.) was taken and stirred at a speed of $1,500 \mathrm{rpm} / \mathrm{min}$, following by addition of further proportion of CS with $0.1 \mathrm{ml} \mathrm{ZnSO}_{4}$, which were stirred continuously for $30 \mathrm{~min}$. Thereafter, the microsphere was moved to a centrifuge tube which was supplemented with $5 \%$ mannitol and then centrifuged for $15 \mathrm{~min}$ at $4^{\circ} \mathrm{C}$, $15,000 \mathrm{rpm} / \mathrm{min}$. The supernatant was discarded and the microsphere was lyophilized for use after centrifugation.

Preparation of CS/DS/rhBMP-2 microsphere. After preparation of CS and DS solutions as described above, $0.2 \mathrm{ml}$ DS and $0.04 \mathrm{ml}$ rhBMP-2 were added and stirred at a speed of $1,500 \mathrm{rpm}$ for $20 \mathrm{~min}$. Then, $0.12 \mathrm{ml} \mathrm{CS}$ solution was added following with addition of $0.1 \mathrm{~m} \mathrm{ZnSO}_{4} 5$ min later, which were stirred continuously for $30 \mathrm{~min}$. The microsphere was moved to a centrifuge tube which was supplemented with $5 \%$ mannitol and then centrifuged for $15 \mathrm{~min}$ at $4^{\circ} \mathrm{C}, 15,000 \mathrm{rpm} / \mathrm{min}$. The supernatant was discarded and the microsphere were lyophilized for use after centrifugation for three times.

Characterization of $C S / D S / r h B M P-2$ microsphere. The average particle size of CS/DS/rhBMP-2 nanoparticles, particle size distribution, and the dispersion of potential value were evaluated. The DS and CS solutions were added with a pipette according to a certain mass ratio (10:1 10:11), and were stirred to form a uniform state at room temperature to obtain the DS/CS complex solution. Analyzing grain diameter of DS/CS blank microsphere was conducted by Zeta potential to determine the best quality ratio. According to above experiment, the DS:CS ratio was set to 10:6, and the ratio of DS:CS:rhBMP-2 was set to 10:6:1, 10:6:1.2, 10:6:1.5, 10:6:2, 10:6:2.5, 10:6:3 to find the optimized mass ratio.

The microsphere morphology of the CS/DS/rhBMP-2 microsphere was observed by a scanning electron microscope (S-4800; Hitachi, Ltd., Tokyo, Japan) and a three-dimensional morphology was obtained using an atomic force microscope (S-5500; Hitachi, Ltd.). Briefly, the CS/DS/rhBMP-2 microsphere solution was dropped on a uniformly thin layer on a silicon wafer after diluted, and then was observed after freeze-drying. Then, a high-resolution Zeta potential and particle size analyzer (Brookhaven American Company) was used to determine the average particle size, size distribution, and the potential of the dispersion of potential value.

Determination of the entrapment efficiency and drug loading ratio. The supernatant liquid was collected after centrifugation. The drug loading rate and entrapment efficiency of rhBMP-2 CS nanoparticles were calcula ted by detecting the amount of rhBMP-2 in the supernatant with Enzyme-linked immunosorbent assay (ELISA) kit (RayBiotech, Norcross, GA, USA). The absorbance [optical density (OD)] of the supernatant was determined at value A450 according to ELISA kit instructions and the standard curve was drawn. All experiments were performed in triplicate. Calculation formulas for entrapment efficiency and drug loading ratio were as follows:

$$
\begin{gathered}
\text { Drug loading }=\frac{(\text { Total quality of } r h B M P-2)-(\text { rhBMP }-2 \text { inupernatants })}{\text { Total quality of microspheres }} \times 100 \% \\
\text { Entrapment efficiency }=\frac{(\text { Total quality of } r h B M P-2)-(\text { rhBMP }-2 \text { insupernatants })}{\text { Total quality of } r h B M P-2} \times 100 \%
\end{gathered}
$$

In vitro sustained release profile. $50 \mathrm{mg}$ CS/DS/rhBMP-2 microsphere was added with $2 \mathrm{ml}$ phosphate buffer solution with $\mathrm{pH} 7.4$, following with ultrasonic vibration at room temperature for $10 \mathrm{~min}$. The solution was centrifuged for $15 \mathrm{~min}$ at the speed of $15,000 \mathrm{rpm} / \mathrm{min}$. $100 \mathrm{ml}$ supernatant 
was taken at $6,12,18,24,48$, and 72 h every 3 days and was ultrasonically oscillated with $100 \mathrm{ml}$ PBS. The content of rhBMP-2 in the supernatant was measured by ELISA kit as described above. All experiments were performed in triplicate.

\section{Biocompatibility assessment}

Extracts preparation. 1 g CS/DS/rhBMP-2 composite microsphere and $1 \mathrm{~g} \mathrm{CS} / \mathrm{DS}$ sample blank microsphere were added into two flasks respectively, following by addition of $40 \mathrm{ml}$ RPMI1640 medium ml (Gibco; Thermo Fisher Scientific, Inc., Waltham, MA, USA) to each flask. The flasks were placed in a cell incubator $\left(37^{\circ} \mathrm{C}, 5 \% \mathrm{CO}_{2}\right)(\mathrm{V} / \mathrm{V})$ and were cultured for $24 \mathrm{~h}$, sterilized by microporous membrane $(0.22 \mu \mathrm{m})$, and stored at $4^{\circ} \mathrm{C}$.

Cell culture. The L929 cells (provided by General Hospital of Guangzhou Military Command, department of Experimental Medicine) were thawed $1 \sim 2 \mathrm{~min}$ at $37^{\circ} \mathrm{C}$ water bath, and then $15 \mathrm{ml}$ L929 cells liquid were sterilized $30 \mathrm{~min}$ using the UV ultra-bacteria station. Cells were then centrifuged for $5 \mathrm{~min}, 1,000 \mathrm{rpm} / \mathrm{min}$. The supernatant was discarded, and cells were re-suspended with the H-DMEM medium (Gibco; Thermo Fisher Scientific, Inc.) containing 10\% fetal bovine serum (FBS) (V/V) (Gibco; Thermo Fisher Scientific, Inc.), and cultured at the condition of $37^{\circ} \mathrm{C}, 5 \% \mathrm{CO}_{2}$. Cells in the logarithmic phase were trypsinized and formulated into cell suspension of concentration of $1 \times 10^{4} / \mathrm{ml}$. Then cells were seeded in 96-well culture plate with $100 \mu \mathrm{l}$ per hole and cultured under $37^{\circ} \mathrm{C}, 5 \% \mathrm{CO}_{2}$.

MTT assay. Samples were divided into CS/DS/rhBMP-2 composite microsphere (200 ng/ml) group, rhBMP-2 (200 ng/ml group, CS/DS blank microsphere $(200 \mathrm{ng} / \mathrm{ml})$ group and control group; each group contained three parallel samples. $10 \mu \mathrm{l}$ MTT $(5 \mathrm{mg} / \mathrm{ml})$ was added for each group at $1,3,5,7$ days. The relative growth rate (RGR of each group of cells was detected at the OD of 490 after cultured for $4 \mathrm{~h}$, namely (experimental group OD/negative control OD x100\%.

Cytotoxicity evaluation. Cytotoxicity was evaluated according to the United States Pharmacopoeia cytotoxic grading standards (32), 0 level: RGR $\geq 100$; 1 level: 75 99; 2 level: 50 74; 3 level: 25-49; 4 level: 2 14; 5 level: 0 .

Differentiation and proliferation studies of BMSCs-C57 cells BMSCs-C57 subculture experiments. Cells were divided into four groups: CS/DS/rhBMP-2 microsphere group, added with CS/DS/rhBMP-2 composite microsphere (concentration of the drug in accordance with the conversion rate, rhBMP-2 concentration of $200 \mu \mathrm{g} / \mathrm{l}$ ); rhBMP-2 group, added with rhBMP-2 (200 $\mu \mathrm{g} / \mathrm{l})$; CS/DS group, added with CS/DS microsphere; blank control group. Cultured the BMSCs-C57 of third generation was cultured, and the growth of cells was observed every day. Cells were cultured after digestion with $0.25 \%$ trypsin when convergence rate $>80 \%$.

Proliferation assessment of BMSCs-C57cells. Proliferation of BMSCs-C57 cells was determined using MTT method. Cell culture and MTT procedure were described as above. Cell proliferation in each group was determined at 2, 4 and 6 days.

Differentiation analysis of BMSCs-C57 cells. The differentiation analysis of BMSCs-C57 cells was conducted by detecting the alkaline phosphatase (ALP) activity of different groups of cells when cultured at 1, 3, 5, 7, 9, 11 and 14 days using an Alkaline Phosphatase Detection Kit (Nanjing built Biotechnology Co., Ltd., China). The growth of calcium nodules in each group was observed by alizarin red staining.

Statistical analysis. Results were expressed as mean \pm standard deviation (SD) from three or more separate experiments. All the data were analyzed by SPSS v19.0 statistic package software. The statistical differences were analyzed by using the ANOVA test. Pairwise comparisons in two groups were analyzed by the Student's t-test. $\mathrm{P}<0.05$ was considered to indicate a statistically significant difference.

\section{Results}

Characterization and optimization of microspheres. Representative SEM images of CS/DS/rhBMP-2 are shown in Fig. 1. It could be observed that prepared CS/DS/rhBMP-2 nano-composites with smooth surfaces were spherical and evenly disperses without obvious agglomeration, which suggested the successful formation of the microspheres. As shown in Table I, the diameter of the CS/DS/rhBMP-2 microsphere could be adjusted between $200 \mathrm{~nm} \sim 900 \mathrm{~nm}$. When the mass ratio of DS and CS was 10:1, the grain diameter was larger than $1 \mu \mathrm{m}$. The diameter of CS/DS microsphere was $928.2 \pm 8.8 \mathrm{~nm}$ when mass ratio of DS:CS was 10:2. It was found that the increase of CS/DS mass ratio would lead to decrease of the diameter of the resulting microsphere. When the mass ratio of DS/CS reached 10:6, the particle diameter of the microsphere was around $217 \mathrm{~nm}$ and the polydispersity was the narrowest $(0.221 \pm 0.008)$. The particle diameter of CS/DS microsphere increased when more CS was added. When mass ratio of DS:CS was over 10:10, the diameter of CS/DS microsphere was larger than $1 \mu \mathrm{m}$.

Table II shows the average particle size, degree of dispersion and Zeta potential values of CS/DS/rhBMP-2 microspheres with different DS: CS: rhBMP-2 mass ratios. It was found that when the mass ratio of DS: CS: rhBMP-2 was 10: 6: 1.2, the average particle size of CS/DS/rhBMP-2 microsphere is about $248.1 \mathrm{~nm}$, polydispersity was about 0.188 , Zeta potential value was about $-9.55 \mathrm{mV}$. Under this mass ratio, CS/DS/rhBMP-2 microspheres had the optimized stability, good dispersion and the appropriate diameter for delivery purpose, which were used for our further studies.

Drug loading ratio, entrapment efficiency and release Kinetics of $r h B M P-2$. CS/DS/microspheres showed the highest entrapment efficiency of $85.6 \pm 3 \%$, and the highest the drug loading ratio (rhBMP-2 to CS/DS/microspheres of $47.245 \pm 3.321 \mu \mathrm{g} / \mathrm{mg}$ ). It was observed that the microsphere release started to undergo a sudden release period in vitro $2 \mathrm{~h}$ after the experiment, and the release concentration reached a peak at day 4 , followed by a slow decline. The release cycle lasted about 20 days, which was well consistent with a biphasic release kinetic model (Fig. 2). 
Table I. Grain diameter, dispersion and Zeta potential values of DS/CS microsphere under different mass ratios of DS:CS.

R(DS:CS) Particle (nm) Polydispersity Zeta potential (mV)

\begin{tabular}{llll}
\hline $10: 2$ & $928.2 \pm 8.8$ & $0.205 \pm 0.012$ & $-23.82 \pm 0.68$ \\
$10: 3$ & $725.1 \pm 12.8$ & $0.212 \pm 0.017$ & $-16.24 \pm 3.25$ \\
$10: 5$ & $212.3 \pm 11.5$ & $0.214 \pm 0.004$ & $-16.61 \pm 1.57$ \\
$10: 6$ & $217.2 \pm 15.7$ & $0.221 \pm 0.008$ & $-16.50 \pm 0.76$ \\
$10: 9$ & $930.7 \pm 14.5$ & $0.061 \pm 0.072$ & $-11.35 \pm 5.60$ \\
\hline
\end{tabular}

Data are presented as the mean \pm standard deviation. CS, chitosan; DS, dextran sulfate.

Table II. Grain diameter, dispersion and Zeta potential values of CS/DS/rhBMP-2 microsphere under different mass ratios of DS:CS:rhBMP-2.

\begin{tabular}{lllr}
\hline $\begin{array}{l}\text { R(DS:CS: } \\
\text { rhBMP-2) }\end{array}$ & Particle (nm) & Polydispersity & $\begin{array}{c}\text { Zeta } \\
\text { Potential }(\mathrm{mV})\end{array}$ \\
\hline $10: 6: 1$ & $247.9 \pm 10.8$ & $0.121 \pm 0.032$ & $-15.61 \pm 1.75$ \\
$10: 6: 1.2$ & $248.1 \pm 2.7$ & $0.188 \pm 0.012$ & $-9.55 \pm 1.54$ \\
$10: 6: 1.5$ & $264.6 \pm 2.4$ & $0.122 \pm 0.048$ & $-9.88 \pm 2.69$ \\
$10: 6: 2$ & $259.3 \pm 3.1$ & $0.182 \pm 0.023$ & $-8.40 \pm 1.81$ \\
$10: 6: 2.5$ & $252.5 \pm 3.2$ & $0.167 \pm 0.002$ & $-7.96 \pm 4.22$ \\
$10: 6: 3$ & $266.2 \pm 2.4$ & $0.185 \pm 0.017$ & $-17.80 \pm 0.49$ \\
\hline
\end{tabular}

Data are presented as the mean \pm standard deviation. CS, chitosan; DS, dextran sulfate; rhBMP-2, recombinant human bone morphogenetic protein 2 .

$C S / D S /$ and CS/DS/rhBMP-2 microspheres had no effect on BMSCs-C57 cells proliferation. MTT assay was conducted to measure the effect of different kinds of microspheres on BMSCs-C57 cells. Results showed that in all cell groups, the cell morphology were normal, fusiform or polygonal, cell bodies were plump and no significant difference were noticed among the groups (Fig. 3), suggesting that microspheres didn't show significant effect on cells. After cultured 2, 4, 6 days, results of OD values of all BMSCs-C57 cells also showed no significant difference $(\mathrm{P}>0.05$, Table III).

Effect of CS/DS/ and CS/DS/rhBMP-2 microspheres on differentiation of BMSCs-C57 cells. To investigate the effects of different microspheres on differentiation of BMSCs-C57 cells, the ALP assay of BMSCs-C57 cells and alizarin red staining were performed. Results showed that in CS/DS/rhBMP-2 microsphere group, ALP activity was significantly lower than rhBMP-2 group, $(\mathrm{P}<0.05$, Table IV and Fig. 4), but when cultured 5 days, the ALP activity of CS/DS/rhBMP-2 microsphere group was significantly higher than other 3 groups $(\mathrm{P}<0.05$, Table IV and Fig. 4$)$; and the ALP activity of BMSCs-C57 in rhBMP-2 group was significantly higher than CS/DS group and control group, $(\mathrm{P}<0.05$, Table IV and Fig. 4). These results suggested that $\mathrm{CS} / \mathrm{DS} / \mathrm{rhBMP}-2$ microsphere had stronger ability to induce
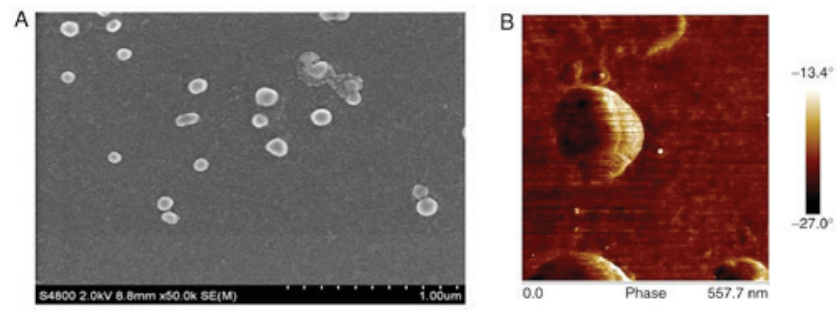

Figure 1. (A) Scanning electron microscope images and (B) atomic force microscopy images of CS-DS/rhBMP-2 microspheres. CS, chitosan; DS, dextran sulfate ; recombinant human bone morphogenetic protein 2 .

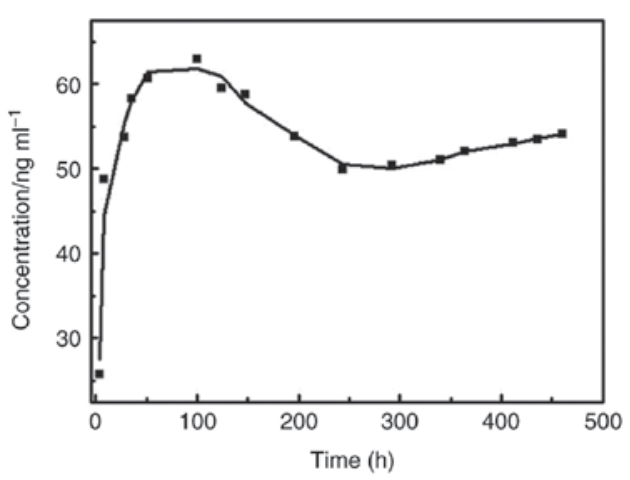

Figure 2. rhBMP-2 release profiles for CS-DS. Data are presented as the mean \pm standard deviation $(n=3)$. rhBMP-2, recombinant human bone morphogenetic protein 2. CS, chitosan; DS, dextran sulfate.
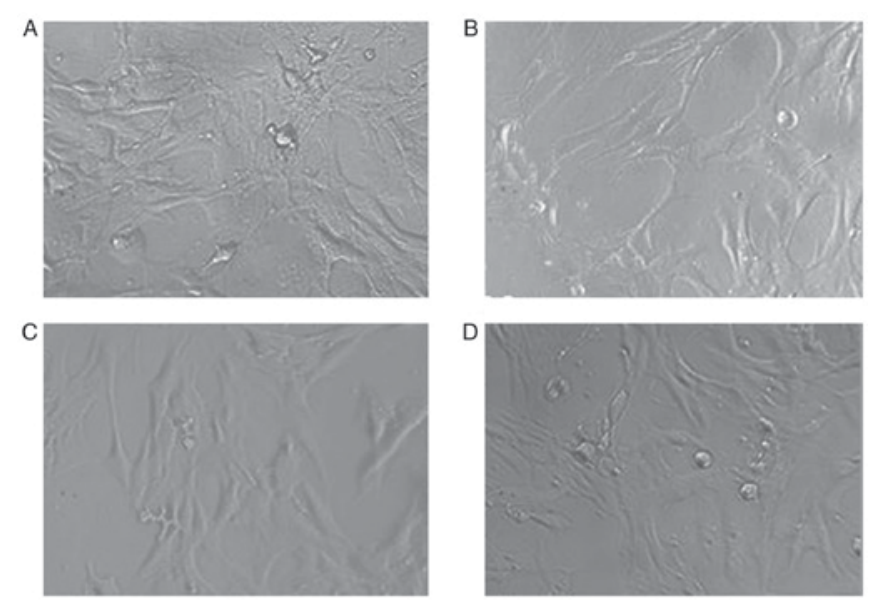

Figure 3. Microscopic images of BMSCs-C57 in the (A) CS/DS/rhBMP-2, (B) rhBMP-2, (C) CS/DS (D) and control groups (magnification, x200). CS, chitosan; DS, dextran sulfate; rhBMP-2, recombinant human bone morphogenetic protein 2 .

ALP activity in a long term period. Results of alizarin red staining also showed that after osteogenic culturing for 14 days, clear crystal formation in BMSCs-C57 cells could be found in CS/DS/rhBMP-2 microsphere group and rhBMP-2 group. Cells showed multilayered structure and granular materials could be seen clearly on the cell surface. However there was no appreciable formation of calcium nodules in CS/DS group and the control group (Fig. 5), which further demonstrated the differentiation induction ability of CS/DS/rhBMP-2 microsphere. 
Table III. Optical density values of BMSC-C57 at different time points of the different groups co-cultured with bone marrow mesenchymal stem cells-C57.

Culture time (days)

\begin{tabular}{llll}
\cline { 2 - 4 } Group & \multicolumn{1}{c}{2} & 4 & 6 \\
\hline CS/DS/rhBMP-2 microsphere & $0.606 \pm 0.054$ & $1.266 \pm 0.124$ & $2.752 \pm 0.254$ \\
rhBMP-2 & $0.632 \pm 0.076^{\mathrm{a}}$ & $1.256 \pm 0.142^{\mathrm{a}}$ & $1.985 \pm 0.171^{\mathrm{a}}$ \\
CS/DS & $0.574 \pm 0.027^{\mathrm{a}}$ & $1.196 \pm 0.054^{\mathrm{a}}$ & $1.984 \pm 0.100^{\mathrm{a}}$ \\
Blank control & $0.611 \pm 0.063^{\mathrm{a}}$ & $1.105 \pm 0.112^{\mathrm{a}}$ & $2.325 \pm 0.245^{\mathrm{a}}$
\end{tabular}

Data are presented as the mean \pm standard deviation $(\mathrm{n}=4) .{ }^{\mathrm{a}} \mathrm{P}<0.05$ vs. $\mathrm{CS} / \mathrm{DS} / \mathrm{rhBMP}-2$ group. $\mathrm{CS}$, chitosan; DS, dextran sulfate; rhBMP-2, recombinant human bone morphogenetic protein 2 .

Table IV. Alkaline phosphatase activity of bone marrow mesenchymal stem cells-C57 in each group.

\begin{tabular}{lccccccc}
\hline & \multicolumn{7}{c}{ Training time (days) } \\
\cline { 2 - 8 } Group & 1 & 3 & 5 & 7 & 9 & 11 & 14 \\
\hline CS/DS/rhBMP-2 & $0.103 \pm 0.003$ & $0.151 \pm 0.009$ & $0.293 \pm 0.006$ & $0.325 \pm 0.007$ & $0.337 \pm 0.008$ & $0.375 \pm 0.007$ & $0.412 \pm 0.005$ \\
microsphere & & & & & & \\
rhBMP-2 & $0.105 \pm 0.007$ & $0.193 \pm 0.005^{\mathrm{a}}$ & $0.215 \pm 0.009^{\mathrm{a}}$ & $0.217 \pm 0.007^{\mathrm{a}}$ & $0.217 \pm 0.007^{\mathrm{a}}$ & $0.248 \pm 0.008^{\mathrm{a}}$ & $0.283 \pm 0.010^{\mathrm{a}}$ \\
CS/DS & $0.103 \pm 0.009$ & $0.107 \pm 0.005^{\mathrm{a}, \mathrm{b}}$ & $0.107 \pm 0.009^{\mathrm{a}, \mathrm{b}}$ & $0.107 \pm 0.008^{\mathrm{a}, \mathrm{b}}$ & $0.117 \pm 0.009^{\mathrm{a}, \mathrm{b}}$ & $0.117 \pm 0.009^{\mathrm{a}, \mathrm{b}}$ & $0.161 \pm 0.019^{\mathrm{a}, \mathrm{b}}$ \\
Blank control & $0.105 \pm 0.007$ & $0.105 \pm 0.009^{\mathrm{a}, \mathrm{b}}$ & $0.108 \pm 0.004^{\mathrm{a}, \mathrm{b}}$ & $0.109 \pm 0.003^{\mathrm{a}, \mathrm{b}}$ & $0.117 \pm 0.009^{\mathrm{a}, \mathrm{b}}$ & $0.137 \pm 0.009^{\mathrm{a}, \mathrm{b}}$ & $0.141 \pm 0.004^{\mathrm{a}, \mathrm{b}}$ \\
F-value & 0.525 & 11.029 & 14.422 & 21.819 & 22.577 & 23.894 & 23.076 \\
P-value & 0.618 & $<0.001$ & $<0.001$ & $<0.001$ & $<0.001$ & $<0.001$ & $<0.001$ \\
\hline
\end{tabular}

Data are presented as the mean \pm standard deviation optical densitys values $(\mathrm{n}=4)$. ${ }^{\mathrm{a}} \mathrm{P}<0.05$ vs. $\mathrm{CS} / \mathrm{DS} / \mathrm{rhBMP}-2$ group; ${ }^{\mathrm{b}} \mathrm{P}<0.05$ vs. $\mathrm{rhBMP}-2$ group. CS, chitosan; DS, dextran sulfate; rhBMP-2, recombinant human bone morphogenetic protein 2.

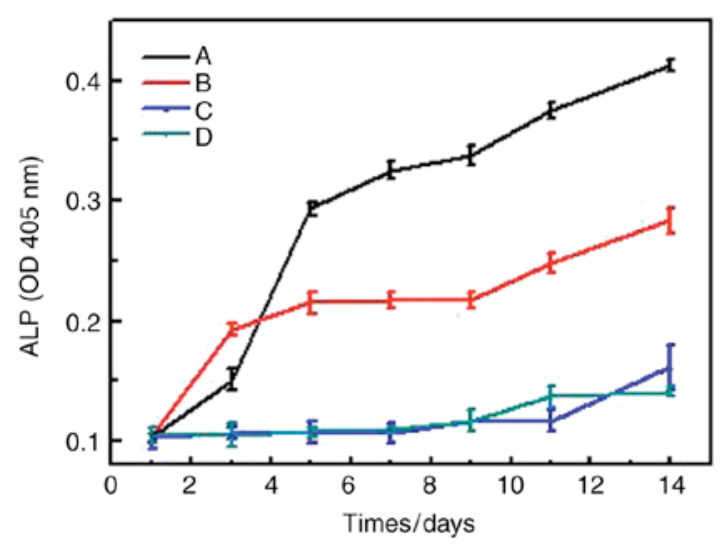

Figure 4. Trend graph of the ALP activity of bone marrow mesenchymal stem cells-C57 in each group. Data are presented as the mean \pm standard deviation $(n=4)$. A, CS/DS/rhBMP-2 microsphere group; B, rhBMP-2 group; C, CS/DS group; D, control group; ALP, alkaline phosphatase; CS, chitosan; DS, dextran sulfate; rhBMP-2, recombinant human bone morphogenetic protein 2; OD, optical density.

The biocompatibility of $C S / D S / r h B M P-2$ microsphere. At last we determined The biocompatibility of CS/DS/rhBMP-2 microsphere using toxicity test. Morphology study showed that the sub-cultured L929 cells were fully extended, spindle or polygonal and the nuclei were clear to be seen and appeared circular or oval (Fig. 6). The results of the cytotoxicity evaluation carried on L929 cells were shown in Table V and Fig. 7. After incubation for 7 days, there was no significant difference in OD values for CS/DS/rhBMP-2 microsphere group and other groups $(\mathrm{P}>0.05$. And the toxicity grading was between level 0 and 1 . These results indicated that CS/DS/rhBMP-2 microsphere and CS/DS blank microsphere $(200 \mathrm{ng} / \mathrm{ml})$ were not toxic to L929 cells in the concentrations studied.

\section{Discussion}

Microspheres are known as carriers to significantly enhance the efficacy of loaded therapeutics (33). In this study, we employ an organic solvent-free method to fabricate CS/DS polyelectrolyte complex based microspheres that can efficiently entrap and stabilize rhBMP-2 protein. BMP-2 was first bound to anionic DS, DS sodium, with its heparin binding domain, then forms polyelectrolyte complex with a cationic polymer, $\mathrm{CS}$, to form the protein-loaded CS/DS microspheres (28). The morphology and size of resultant CS/DS/rhBMP-2 microsphere were characterized and results showed that the protein-loaded CS/DS microspheres had smooth surfaces and evenly dispersed without obvious agglomeration in solution, suggesting successfully construction of the delivery system. The diameter of the CS/DS/rhBMP-2 microsphere can be adjusted between 200 to $900 \mathrm{~nm}$ the optimized 

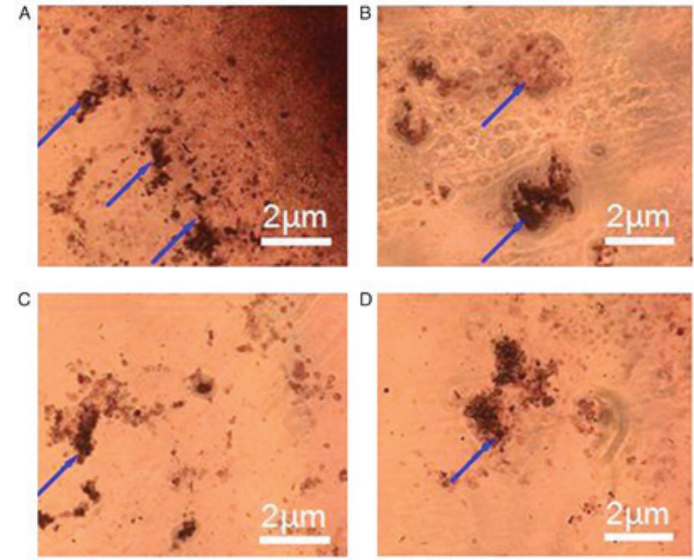

Figure 5. Microscopic images of Alizarin Red staining displaying the formation of calcium nodules in BMSCs-C57 cells following osteogenic culturing for 14 days in (A) CS/DS/rhBMP-2 microsphere group, (B) rhBMP-2 group, (C) CS/DS group and (D) control group. Blue arrows indicate calcium nodules. Scale bars $=2 \mu \mathrm{m}$. CS, chitosan; DS, dextran sulfate; rhBMP-2, recombinant human bone morphogenetic protein 2 .

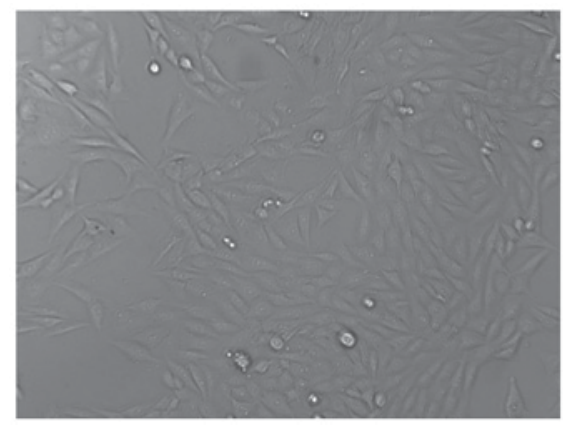

Figure 6. Microscopic image of recovered sub-cultured L929 cells (magnification, $\mathrm{x} 200)$.

mass ratio of DS:CS:rhBMP-2 was found to be 10: 6: 1.2. At this mass ratio, the average particle size of CS/DS/rhBMP-2 microsphere was about $248.1 \mathrm{~nm}$, the polydispersity was around 0.188 and Zeta potential value was $-9.55 \mathrm{mV}$.

Then, the entrapment efficiency, drug loading rate, and in vitro release profile of the CS/DS/rhBMP-2 microspheres were assessed by an enzyme-linked immunosorbent assay (ELISA). The entrapment efficiency and protein to carrier loading ratio were found to be $85.6 \%$ and $47.245 \mathrm{ug} / \mathrm{mg}$, respectively, which were higher than that of CS/BMP-2 microsphere. It confirmed our hypothesis that introduction of DS as the BMP-2 binding component to our CS based delivery vehicle could greatly enhance the encapsulation efficiency and protein to carrier loading ratio. The results of in vitro release studies suggested that burst effect of loaded microsphere was avoided. In fact, around $20 \%$ of entrapped protein was released in the first two hour and at day 4 , the release reached a peak, followed by a slow decline. The release lasted about 20 days, which is in consistent with a biphasic release kinetic model. It was likely that the observed release in first 4 days could be attributed to the relatively weak binding force between CS and rhBMP-2 in the microspheres. After that, rhBMP-2 that was strongly bounded with DS was gradually released. Next, the cell cytotoxicity of the CS/DS/rhBMP-2 microsphere to the mouse fibroblasts L929
Table V. Optical density values, relative growth ratio and toxicity grading of each group following incubation with L929 cells.

\begin{tabular}{llcc}
\hline Group & Optical density & $\begin{array}{c}\text { Relative growth } \\
\text { ratio (\%) }\end{array}$ & $\begin{array}{c}\text { Toxicity } \\
\text { grading }\end{array}$ \\
\hline $\begin{array}{l}\text { CS/DS/rhBMP-2 } \\
\text { microsphere }\end{array}$ & $0.468 \pm 0.0123$ & 102.41 & 0 \\
rhBMP-2 & $0.454 \pm 0.0161$ & 99.34 & 1 \\
CS/DS & $0.470 \pm 0.00723$ & 102.85 & 0 \\
Blank control & $0.457 \pm 0.00265$ & 100.00 & 0 \\
\hline
\end{tabular}

Data are presented as the mean \pm standard deviation $(n=3)$. CS, chitosan; DS, dextran sulfate; rhBMP-2, recombinant human bone morphogenetic protein 2 .

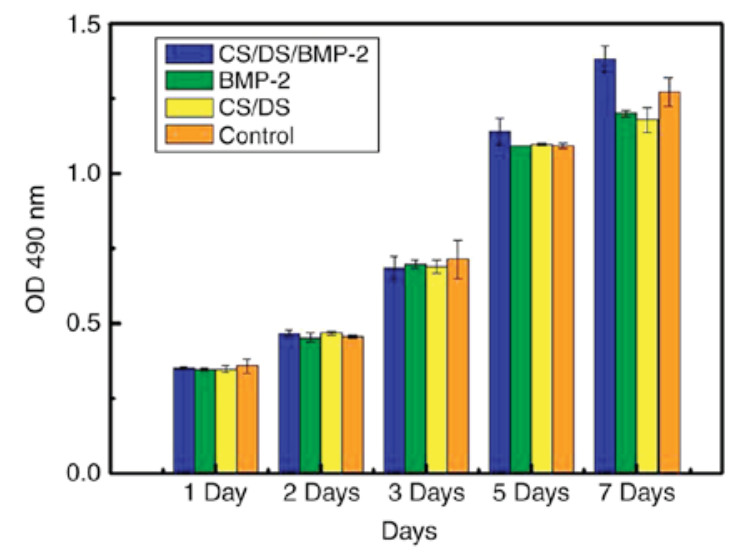

Figure 7. Cytotoxicity influence on L929 cells in each group at different time points revealed by an MTT assay. Data are presented as the mean \pm standard deviation. CS, chitosan; DS, dextran sulfate; rhBMP-2, recombinant human bone morphogenetic protein 2; OD, optical density.

cell was assessed by MTT assay. The data showed that the RGR value of CS/DS/rhBMP-2 microsphere is $102.41 \%$, the cytotoxicity level is 0 . The OD values of CS/DS/rhBMP-2 microsphere group and DS/CS blank microsphere group co-cultured with L929 were not statistically significant, $P>0.05$, and the toxicity grading was found to be between 0 and 1 . These results indicated that CS/DS/rhBMP-2 microsphere had good biocompatibility.

The osteogenic effect of CS/DS/rhBMP-2 microsphere on bone marrow stromal cells (BMSCs-C57) was investigated. BMSCs are widely used as seed cells for tissue engineering. Also, they possess multiple differentiation potential and can be induced to differentiate into a variety of cell types $(34,35)$. It is known that BMP-2 can induce BMSC's differentiation, stimulate ALP activities and matrix calcification (36). In CS/DS/rhBMP-2 group, rhBMP-2 group, CS/DS group and negative control group, the form of cells in each group looked fusiform or polygonal, cell body appeared plump, and the cell nucleus were found to be large and clear, no significant differences among the four groups were observed. In addition, there were no significant differences $(\mathrm{P}>0.05)$ in the $\mathrm{OD}$ values of each group. These results suggested that rhBMP-2 loaded CS/DS microsphere, CS/DS microsphere, and free rhBMP-2, 
do not have significantly effect of promoting the proliferation of BMSCs-C57. ALP, as a biological mineralization marker, ALP assay is usually used to verify cell osteogenic transformation and matrix calcification osteoinductive (37). RhBMP-2 loaded CS/DS microspheres were found to induce increase of ALP level in BMSCs-C57, which indicated that they had significantly ability of promoting differentiation of BMSCs, which might be due to controlled release of rhBMP-2 from the microspheres. In contrary, rhBMP-2, blank CS/DS microsphere and the control group did not show appreciable differentiation of BMSCs. Herford et al (38), demonstrated that the addition of rhBMP2 into the between of the bone fragment induced a rapid increase in hard and soft tissue healing, which is in consistent with our study. Calcium nodule formation were checked with an optical microscope by Alizarin Red staining protocol, it was found that, no calcium nodules after incubation for 7 days in any groups. After 14 days, the calcium nodule growth in the group of rhBMP-2 loaded CS/DS microsphere could be clearly observed but not in the rhBMP-2 group, CS/DS blank microsphere group or control group, which suggested that rhBMP-2 loaded CS/DS microsphere were able to promoted calcium nodule formation in BMSC cells. All these results verified our assumption that the polyelectrolyte complexes formed between CS and DS indeed significantly increase the osteogenic activity of the encapsulated BMP-2 protein.

The present study also has some limitations. First, we only used ALP activity and the growth condition of calcium nodules to demonstrate the effects of rhBMP-2 CS nanoparticles on cell differentiation and didn't investigate alteration of differentiation related proteins. Secondly, it is unclear that which signaling pathways are involved in the progress for the regulation of rhBMP-2 CS nanoparticles on the cell differentiation. At last the potential clinical use for rhBMP-2 CS nanoparticles is still far away and needs further studies to improve the process.

In summary, DS-CS microspheres were prepared by an ionic cross-linking method. The resultant microsphere could efficiently entrap rhBMP-2 and formed stable rhBMP-2 loaded CS/DS microspheres. By varying mass ratio of DS:CS:rhBMP-2, stable microspheres with suitable particle size could be fabricated. Sustained release of rhBMP-2 from the CS/DS microspheres was observed. RhBMP-2 loaded CS/DS microspheres showed good bio-compatibility and could increase the osteogenic activity of the encapsulated BMP-2. Our results suggested that microspheres from CS/DS based polyelectrolyte complexes might have great potential as carriers of therapeutic proteins in bone tissue engineering.

\section{Acknowledgements}

The present study was supported by the National Natural Science Foundation of China (51303031; Guangdong Natural Science Foundation of China (S2012010009743; Applied basic research project in Guangdong province (2013J4100120).

\section{References}

1. Lalwani G, Henslee AM, Farshid B, Lin L, Kasper FK, Qin YX, Mikos AG and Sitharaman B: Two-dimensional nanostructure-reinforced biodegradable polymeric nanocomposites for bone tissue engineering. Biomacromolecules 14: 900-909, 2013.
2. Xia Z, Yu X, Jiang X, Brody HD, Rowe DW and Wei M: Fabrication and characterization of biomimetic collagen-apatite scaffolds with tunable structures for bone tissue engineering. Acta Biomater 9: 7308-7319, 2013.

3. Petrauskaite O, Gomes Pde S, Fernandes MH, Juodzbalys G, Stumbras $\mathrm{A}$, Maminskas $\mathrm{J}$, Liesiene $\mathrm{J}$ and Cicciù $\mathrm{M}$ : Biomimetic mineralization on a macroporous cellulose-based matrix for bone regeneration. Biomed Res Int 2013: 452750, 2013.

4. Visser R, Rico-Llanos GA, Pulkkinen H and Becerra J: Peptides for bone tissue engineering. J Control Release 244: 122-135, 2016.

5. Rogers GF and Greene AK: Autogenous bone graft: Basic science and clinical implications. J Craniofac Surg 23: 323-327, 2012.

6. Fernandez-Bances I, Perez-Basterrechea M, Perez-Lopez S, Nuñez Batalla D, Fernandez Rodriguez MA, Alvarez-Viejo M, Ferrero-Gutierrez A, Menendez Menendez Y, Garcia-Gala JM, Escudero D, et al: Repair of long-bone pseudoarthrosis with autologous bone marrow mononuclear cells combined with allogenic bone graft. Cytotherapy 15: 571-577, 2013.

7. Feng Y, Wang S, Jin D, Sheng J, Chen S, Cheng X, and Zhang C: Free vascularised fibular grafting with OsteoSet ${ }^{\mathbb{}} 2$ demineralised bone matrix versus autograft for large osteonecrotic lesions of the femoral head. Int Orthop 35: 475-481, 2011.

8. Genuario JW, Faucett SC, Boublik M and Schlegel TF: A cost-effectiveness analysis comparing 3 anterior cruciate ligament graft types: Bone-patellar tendon-bone autograft, hamstring autograft, and allograft. Am J Sports Med 40: 307-314, 2012.

9. Laino L, Iezzi G, Piattelli A, Lo Muzio L and Cicciù M: Vertical ridge augmentation of the atrophic posterior mandible with sandwich technique: Bone block from the chin area versus corticocancellous bone block allograft-clinical and histological prospective randomized controlled study. Biomed Res Int 2014: 982104, 2014.

10. Petite H, Viateau V, Bensaïd W, Meunier A, de Pollak C, Bourguignon M, Oudina K, Sedel L and Guillemin G: Tissue-engineered bone regeneration. Nat Biotechnol 18: 959-963, 2000.

11. Widuchowski W, Widuchowska M, Koczy B, Dragan S, Czamara A, Tomaszewski $\mathrm{W}$ and Widuchowski J: Femoral press-fit fixation in ACL reconstruction using bone-patellar tendon-bone autograft: Results at 15 years follow-up. BMC Musculoskelet Disord 13: 115, 2012.

12. Herford AS, Tandon R, Stevens TW, Stoffella E and Cicciu M: Immediate distraction osteogenesis: The sandwich technique in combination with rhBMP-2 for anterior maxillary and mandibular defects. J Craniofac Surg 24: 1383-1387, 2013.

13. Lissenberg-Thunnissen SN, de Gorter DJ, Sier CF and Schipper IB: Use and efficacy of bone morphogenetic proteins in fracture healing. Int Orthop 35: 1271-1280, 2011.

14. Habibovic P and Barralet JE: Bioinorganics and biomaterials: Bone repair. Acta Biomater 7: 3013-3026, 2011.

15. Tian H, Bi X, Li CS, Zhao KW, Brochmann EJ, Montgomery SR, Aghdasi B, Chen D, Daubs MD, Wang JC and Murray SS: Secreted phosphoprotein $24 \mathrm{kD}$ (Spp24) and Spp14 affect TGF- $\beta$ induced bone formation differently. PLoS One 8: e72645, 2013.

16. Sharma AK, Bury MI, Fuller NJ, Rozkiewicz DI, Hota PV, Kollhoff DM, Webber MJ, Tapaskar N, Meisner JW, Lariviere PJ, et al: Growth factor release from a chemically modified elastomeric poly(1,8-octanediol-co-citrate) thin film promotes angiogenesis in vivo. J Biomed Mater Res A 100: 561-570, 2012.

17. Oryan A, Alidadi S, Moshiri A and Bigham-Sadegh A: Bone morphogenetic proteins: A powerful osteoinductive compound with non-negligible side effects and limitations. Biofactors 40: 459-481, 2014.

18. Martínez A, Arana P, Fernández A, Olmo R, Teijón C and Blanco MD: Synthesis and characterisation of alginate/chitosan nanoparticles as tamoxifen controlled delivery systems. J Microencapsul 30: 398-408, 2013.

19. Cicciù $M$, Herford $A S$, Cicciù $D$, Tandon $R$ and Maiorana $C$ : Recombinant human bone morphogenetic protein-2 promote and stabilize hard and soft tissue healing for large mandibular new bone reconstruction defects. J Craniofac Surg 25: 860-862, 2014.

20. Retraction note: Drying of a plasmid containing formulation: Chitosan as a protecting agent. Daru 24: 11, 2016.

21. Jun SH, Lee EJ, Jang TS, Kim HE, Jang JH and Koh YH: Bone morphogenic protein-2 (BMP-2) loaded hybrid coating on porous hydroxyapatite scaffolds for bone tissue engineering. J Mater Sci Mater Med 24: 773-782, 2013. 
22. Nitta SK and Numata K: Biopolymer-based nanoparticles for drug/gene delivery and tissue engineering. Int J Mol Sci 14: $1629-1654,2013$

23. Cheburu CN, Stoica B, Neamţu A and Vasile C: Biocompatibility testing of chitosan hydrogels. Rev Med Chir Soc Med Nat Iasi 115: 864-870, 2011

24. Honarkar $\mathrm{H}$ and Barikani M: Applications of biopolymers I: Chitosan. Monatshefte für Chemie-Chem Month 140: 1403, 2009.

25. Budiraharjo R, Neoh KG and Kang ET: Enhancing bioactivity of chitosan film for osteogenesis and wound healing by covalent immobilization of BMP-2 or FGF-2. J Biomater Sci Polym Ed 24: 645-662, 2013.

26. Islam MA, Firdous J, Choi YJ, Yun CH and Cho CS: Design and application of chitosan microspheres as oral and nasal vaccine carriers: An updated review. Int J Nanomedicine 7:6077-6093, 2012.

27. Fan H, Li H, Zhang M and Middaugh CR: Effects of solutes on empirical phase diagrams of human fibroblast growth factor 1 . J Pharm Sci 96: 1490-1503, 2007.

28. des Rieux A, Ucakar B, Mupendwa BP, Colau D, Feron O, Carmeliet P and Préat V: 3D systems delivering VEGF to promote angiogenesis for tissue engineering. J Control Release 150: 272-278, 2011.

29. Sullad AG, Manjeshwer LS and Aminabhavi TM: Novel semi-interpenetrating microspheres of dextran-grafted-acrylamide and Poly(Vinyl Alcohol) for controlled release of abacavir sulfate. I \& Eng Chem Res 50: pp11778-11784, 2011.

30. Gribova V, Crouzier T and Picart C: A material's point of view on recent developments of polymeric biomaterials: Control of mechanical and biochemical properties. J Mater Chem 21: 14354-14366, 2011.

31. Hudalla GA and Murphy WL: Biomaterials that regulate growth factor activity via bioinspired interactions. Adv Funct Mater 21: $1754-1768,2011$.
32. Lewis RA (ed). Hawley's Condensed Chemical Dictionary. 16th edition. John Wiley \& Sons, Hoboken, NJ, 2016.

33. Palazzo B, Gallo A, Casillo A, Nitti P, Ambrosio L and Piconi C: Fabrication, characterization and cell cultures on a novel composite chitosan-nano-hydroxyapatite scaffold. Int J Immunopathol Pharmacol 24 (1 Suppl 2): S73-S78, 2011.

34. Raghunath J, Salacinski HJ, Sales KM, Butler PE and Seifalian AM: Advancing cartilage tissue engineering: The application of stem cell technology. Curr Opin Biotechnol 16: 503-509, 2005.

35. Ma HL, Chen TH, Low-Tone Ho L and Hung SC: Neocartilage from human mesenchymal stem cells in alginate: Implied timing of transplantation. J Biomed Mater Res A 74: 439-446, 2005.

36. Majumdar MK, Wang E and Morris EA: BMP-2 and BMP-9 promotes chondrogenic differentiation of human multipotential mesenchymal cells and overcomes the inhibitory effect of IL-1. J Cell Physiol 189: 275-284, 2001.

37. Tsiridis E, Upadhyay N and Giannoudis P: Molecular aspects of fracture healing: Which are the important molecules? Injury 38 (Suppl 1): S11-S25, 2007.

38. Herford AS, Cicciù M, Eftimie LF, Miller M, Signorino F, Famà F, Cervino G, Giudice GL, Bramanti E, Lauritano F, et al: rhBMP-2 applied as support of distraction osteogenesis: A split-mouth histological study over nonhuman primates mandibles. Int J Clin Exp Med 9: 17187-17194, 2016.

(i) (9) This work is licensed under a Creative Commons Attribution-NonCommercial-NoDerivatives 4.0 International (CC BY-NC-ND 4.0) License. 